\title{
Uncarina-Sammlung im Palmengarten
}

\author{
Hilke Steinecke
}

\section{Abstract}

The Palmengarten hosts a good Uncarina collection. It is shortly described.

\section{Zusammenfassung}

Der Palmengarten beherbergt eine gute Uncarina-Sammlung. Diese wird kurz vorgestellt.

Die Gattung Uncarina wird zu den Pedaliaceae (Sesamgewächse) gestellt. In diese Pflanzenfamilie gehört neben dem Sesam auch die als Heilpflanze bekannte Afrikanische Teufelskralle (Harpagophytum procumbens). Uncarina kommt nur auf Madagaskar vor. Es gibt dort etwa 14 Arten, die vom äußersten Norden (Cap d'Ambre) bis in den Süden und Südwesten Madagaskars verbreitet sind. In der botanischen Sammlung des Palmengartens sowie in den Schauhäusern sind alle bekannten UncarinaArten vertreten: Uncarina abbreviata, U. anka- ranensis, $U$. decaryi, U. grandidieri, $U$. ihlenfeldtiana, U. leandrii, U. leptocarpa, U. peltata, $U$. platycarpa, U. perrieri, U. roeoesliana, U. sakalava, U. stellulifera und U. turicana.

Vor allem vom Frühling bis in den Frühsommer hinein können größere blühende Uncarina-Exemplare im Dornwälder-Haus des Tropicariums betrachtet werden.

Es handelt sich um Sträucher oder kleine Bäume bis $8 \mathrm{~m}$ Höhe. Meist ist ihr Stamm an

Abb. 1: Uncarina peltata.

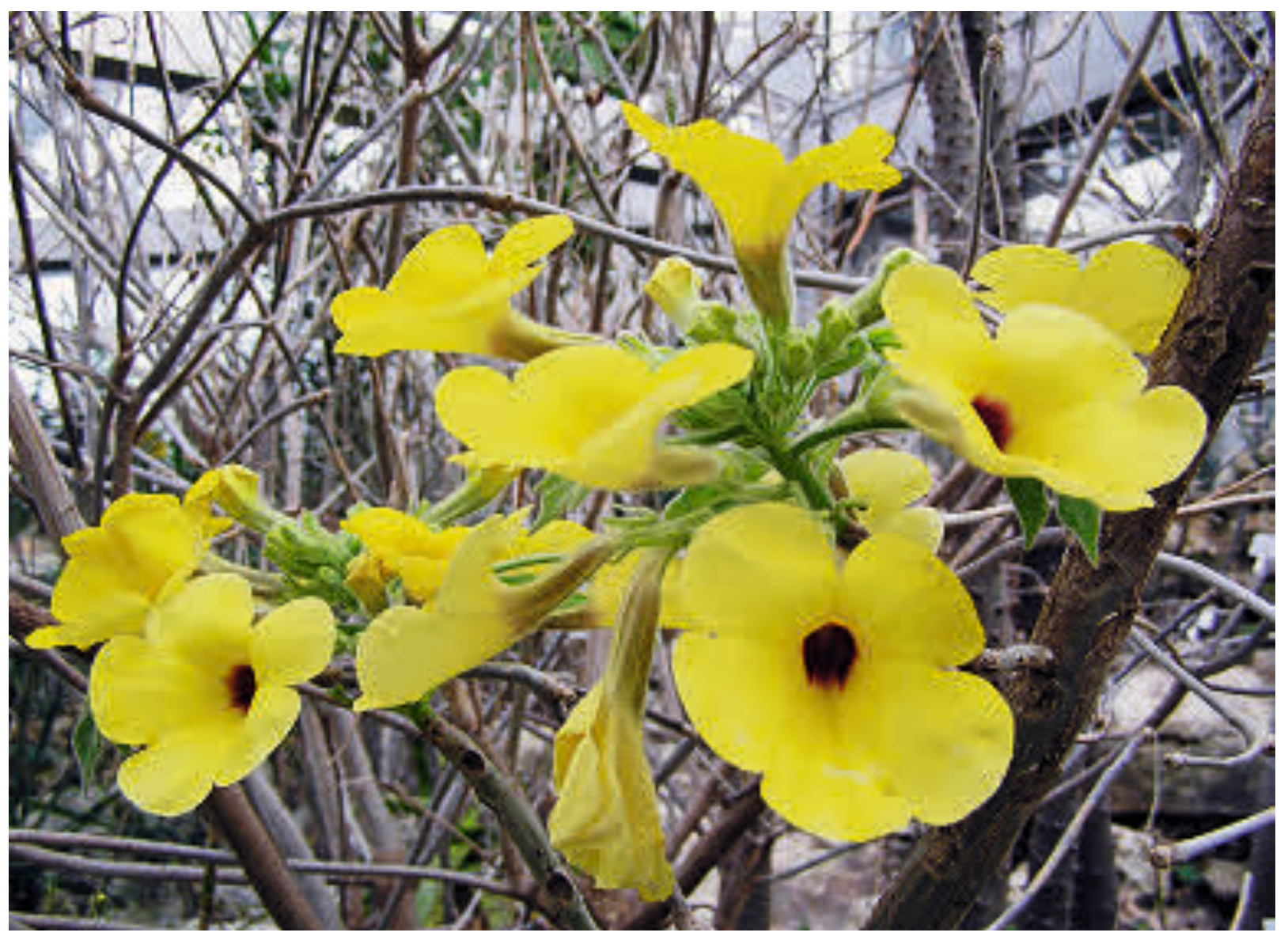



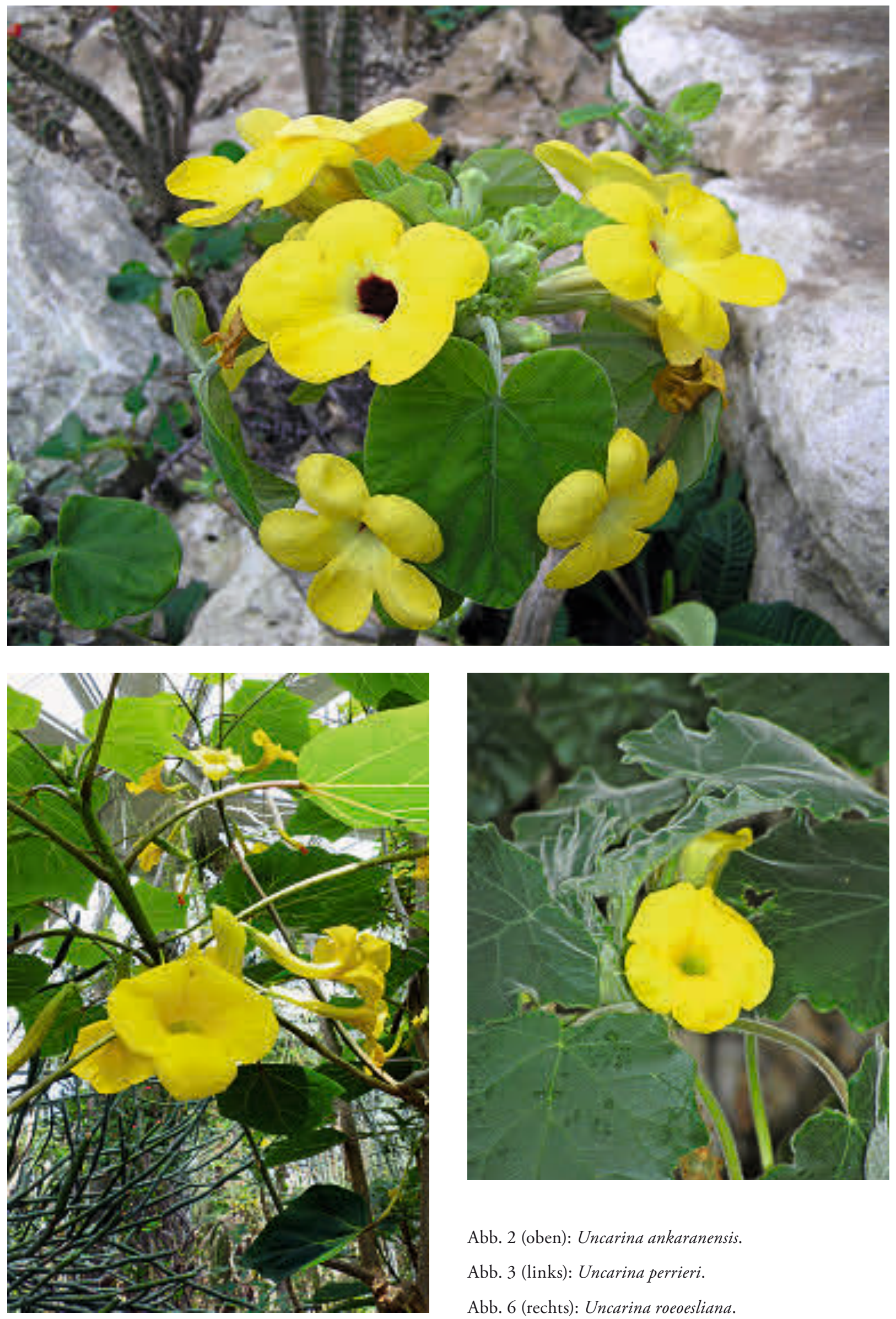

Abb. 2 (oben): Uncarina ankaranensis.

Abb. 3 (links): Uncarina perrieri.

Abb. 6 (rechts): Uncarina roeoesliana. 


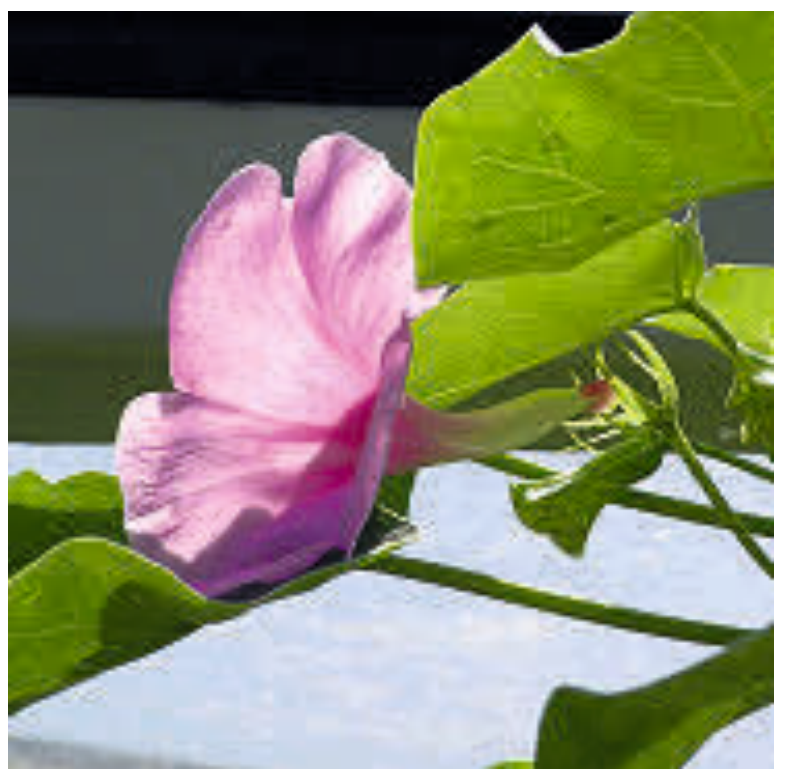

der Basis verdickt und speichert Wasser. Die Blätter sind ganzrandig oder gelappt und werden in der Trockenzeit abgeworfen. Manche erinnern etwas an die Blätter einer Platane oder eines Ahorns.

Die Blüten sind je nach Art gelb, weiß oder rosa gefärbt, oft ist der Schlund dunkel getönt. Die Früchte sind mit Widerhaken versehen, um an Tieren hängenzubleiben. Sie bohren sich aber auch bei nur leichter Berührung sehr fest und schmerzhaft in die Haut, sodass sich die Früchte nur schwer wieder aus ihr herausziehen lassen. Sie ähneln etwas den äußerst unangenehm stechenden Früchten der Teufelskralle. Uncarina ankaranensis wurde erst vor einigen Jahren bei den Tsingys von Ankarana gefunden. Sie unterscheidet sich von anderen Arten durch den meist niederliegenden Wuchs ihrer Hauptachsen; die Seitenachsen wachsen aufsteigend oder aufrecht.

Abb. 4 (oben links): Uncarina abbreviata.

Abb. 5 (oben rechts): Uncarina leptocarpa.

Abb. 7 (Mitte): Uncarina stellulifera mit junger Frucht.

Abb. 8 (unten): Blick in das Dornwälder-Haus mit blühenden Uncarina-Pflanzen.
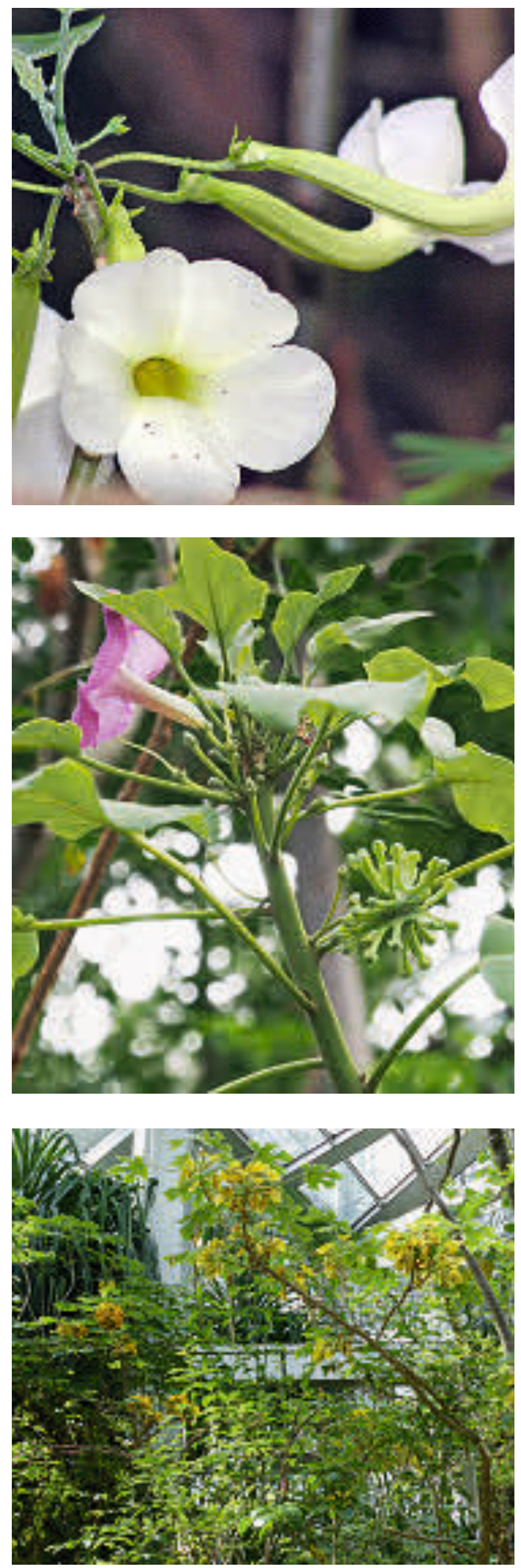